\title{
Salvage radiotherapy after high-intensity focused ultrasound treatment for localized prostate cancer: feasibility, tolerance and efficacy
}

\author{
Thomas Ripert, MD; ${ }^{*}$ Younes Bayoud, MD; ${ }^{*}$ Rabah Messaoudi, MD; Johann Ménard, MD; ${ }^{*}$ Marie-Dominique \\ Azémar, MD; ${ }^{*}$ François Duval, MD; ${ }^{*}$ Tan Dat Nguyen, MD; Frédéric Staerman, MD*
}

Cite as: Can Urol Assoc J 2012;6(5):E179-E183. Epub May 1, 2011. http://dx.doi.org/10.5489/ cuaj. 10137

\section{Abstract}

Background: The objective of this study is to evaluate the feasibility, tolerance and efficacy of salvage external beam radiotherapy (EBRT) in persistent or recurrent prostate cancer after failed high intensity focused ultrasound (HIFU) therapy.

Methods: We reviewed data on tolerance and oncologic outcomes for all patients with biopsy-proven locally recurrent or persistent prostate cancer who underwent salvage EBRT in our department between April 2004 and June 2008. Minimum follow-up for inclusion was 2 years. Failure with EBRT was defined as biochemical relapse (Phoenix definition) or introduction of androgen deprivation therapy (ADT). Gastrointestinal and urinary toxicity and urinary stress incontinence were scored at 12 and 24 months (Radiation Therapy Oncology Group and Ingelman Sundberg rating, respectively).

Results: The mean age of the patients was 68.8 years (range: 60-79). Mean prostate-specific antigen (PSA) before EBRT was $5.57 \mathrm{ng} / \mathrm{mL}$ (range: 2.5-14.8). Median follow-up was $36.5 \pm 10.9$ months (range: 24-54). No patient received adjunctive ADT. The EBRT course was well-tolerated and completed by all patients. The mean PSA nadir was $0.62 \mathrm{ng} / \mathrm{mL}$ (range: 0.03-2.4) and occurred after a median of 22 months (range: 12-36). One patient experienced biochemical failure and was prescribed ADT 30 months after EBRT. The disease-free survival rate was $83.3 \%$ at 36.5 months. There was no major EBRT-related toxicity at 12 or 24 months.

Conclusions: Our early clinical results confirm the feasibility and good tolerance of salvage radiotherapy after HIFU failure. Oncological outcomes were promising. A prospective study with longer follow-up is needed to identify factors predictive of success for salvage EBRT therapy after HIFU failure.

\section{Résumé}

Contexte : L'objectif de l'étude est d'évaluer la faisabilité, la tolérance et l'efficacité $d^{\prime}$ 'une radiothérapie de sauvetage par faisceau externe dans les cas de cancer de la prostate persistant ou récurrent après l'échec $d^{\prime}$ un traitement utilisant des ultrasons ciblés et de haute intensité (HIFU).

Méthodologie : Nous avons examiné les données sur la tolérance et les résultats oncologiques chez tous les patients avec cancer de la prostate récurrent ou persistant comme démontré par biopsie ayant subi une radiothérapie par faisceau externe à notre département entre avril 2004 et juin 2008. Le suivi minimal pour être inclus était de 2 ans. L'échec de la radiothérapie par faisceau externe était défini comme une rechute démontrée par analyses biochimiques (définition de Phoenix) ou l'instauration d'un traitement antiandrogénique. La toxicité gastro-intestinale et urinaire et I'incontinence urinaire d'effort ont été évaluées après 12 et 24 mois (selon la classification du Radiation Therapy Oncology Group et d'Ingelman Sundberg, respectivement).

Résultats : L'âge moyen des patients était de 68,8 ans (intervalle : 60 à 79 ans). Le taux moyen d'antigène prostatique spécifique (APS) avant la radiothérapie par faisceau externe était de $5,57 \mathrm{ng} / \mathrm{mL}$ (intervalle : 2,5 à 14,8). Le suivi moyen était de $36,5 \pm 10,9$ mois (intervalle : 24 à 54). Aucun patient n'a reçu de traitement antiandrogénique d'appoint. La radiothérapie par faisceau externe a été bien tolérée et tous les patients l'ont suivie jusqu'à la fin. Le nadir moyen de l'APS était de $0,62 \mathrm{ng} / \mathrm{mL}$ (intervalle : 0,03 à 2,4 ) et a été observé après une période médiane de 22 mois (intervalle : 12 à 36). Un patient a présenté un échec selon les analyses biochimiques; on lui a prescrit un agent antiandrogénique 30 mois après la radiothérapie par faisceau externe. Le taux de survie sans maladie était de 83,3 $\%$ après 36,5 mois. Aucune toxicité importante en lien avec la radiothérapie n'a été notée après 12 ou 24 mois.

Conclusions : Nos résultats cliniques précoces confirment la faisabilité et la bonne tolérance $d^{\prime}$ une radiothérapie après échec $d^{\prime}$ un traitement HIFU. Les résultats des analyses oncologiques sont prometteurs. Une étude prospective avec un suivi plus long est requise pour cerner les facteurs permettant de prédire la réussite $d^{\prime}$ une radiothérapie par faisceau externe après échec d'un traitement HIFU.

\section{Introduction}

Diagnosis of early prostate cancer is on the increase worldwide, particularly as a result of more widespread prostatespecific antigen (PSA) screening and increased patient awareness. ${ }^{1}$ Primary treatment for localized prostate cancer includes active surveillance, radical prostatectomy (RP) and radiation therapy, including brachytherapy in specific cases. ${ }^{2}$ The goal of therapy is effective cancer control with minimal morbidity.

Recently, new treatments have been developed to minimize the side-effects and complications associated with conventional treatments. High-intensity focused ultrasound 
Ripert et al.

(HIFU) treatment is an emerging, less invasive, alternative procedure. Its feasibility has been established. Acceptable oncologic outcomes have been obtained on first-line HIFU treatment of patients not suitable for surgery or who refused surgery. ${ }^{3-6}$ However, a recent study reported a $46 \%$ failure rate and the authors decided to suspend HIFU treatment pending further evidence of its safety and efficacy. ${ }^{7}$ The positive biopsy rate after first-line HIFU ranges from $7 \%$ to $34 \%$ and the overall 5 -year biochemical-free survival rate ranges from $30 \%$ to $78 \% .^{8-11}$

After 15 years of use, the role of HIFU in the treatment of localized prostate cancer is still a matter of debate.

The European Association of Urology still considers HIFU treatment to be "investigational,"12 and recently, Lukka and colleagues concluded in a systematic review that HIFU was currently not recommended as an alternative to accepted curative treatment approaches for localized prostate cancer. ${ }^{13}$ On the contrary, French and Italian urological association guidelines recommend HIFU as an alternative for patients with localized disease who are unsuitable for radiation therapy or surgery on the basis of evidence showing that HIFU can achieve short-term cancer control. ${ }^{14}$

Moreover, little is known about salvage therapy for the $13 \%$ to $15 \%$ of patients with persistent local disease after HIFU failure. ${ }^{15,16} \mathrm{~A}$ possible salvage therapy is laparoscopic extraperitoneal RP, but the potential of salvage prostatectomy following HIFU has been demonstrated in small groups of patients and many HIFU patients are unsuitable candidates for surgery. ${ }^{17,18}$ Androgen deprivation therapy (ADT) is not curative. Active surveillance is always possible, but external beam radiotherapy (EBRT) has been put forward as a possible option; ${ }^{19}$ to our knowledge, only one study has been published..$^{20}$

Our aim was to review patients who experienced HIFU failure at our institution who underwent salvage EBRT to determine the feasibility, tolerance and oncologic control of post-HIFU EBRT.

\section{Methods}

We retrospectively reviewed the data of all patients with localized prostate cancer who were treated by HIFU (Ablatherm, EDAP-TMS, Lyon, France) at our institution between April 2004 and June 2008. We extracted data on all patients who had experienced failure after the HIFU procedure and who underwent salvage EBRT. We used the Stuttgart definition for biochemical failure after HIFU treatment (i.e., PSA nadir value plus $1.2 \mathrm{ng} / \mathrm{mL}$ ). ${ }^{21}$ Persistent disease or local recurrence was confirmed by positive biopsies.

We used conventional 3D-conformal EBRT for salvage therapy. The pre-treatment computer tomography (CT) scan was used to delineate the clinical tumour volume (CTV), planned tumour volume (PTV) and organs at risk (OAR).
CTV1 comprised the seminal vesicles and the prostate gland. The dose delivered to PTV-1 was 46 Gy in 23 fractions of 2 Gy. CTV2 comprised the prostate gland. The dose to PTV-2 was 74 Gy in 37 fractions of 2 Gy. The OAR were the bladder (wall), rectum (wall), anus, penile bulb and femoral heads. We applied the dose constraints recommended by the French National Cancer Institute (INCa). Photon beams (25 MV energy) were used for all patients. Intensity modulated radiation therapy (IMRT) was not used; image-guided radiation therapy (IGRT) was used in some patients. Portal imaging was performed each week in each patient. Patients were seen weekly by a resident throughout radiotherapy treatment and were followed up at regular intervals after the end of the treatment.

We retrieved data on tolerance and oncologic results (PSA level) from the patients' medical records. Our study included only those patients with complete data and a follow-up of at least 24 months to obtain a true indication of the PSA nadir after EBRT. Our definition of failure after EBRT was either biochemical relapse or the start of ADT. We used the Phoenix definition for biochemical failure, i.e., PSA nadir value plus $2 \mathrm{ng} / \mathrm{mL}^{22}$

During EBRT, patients self-assessed general tolerance as good, moderate or bad. At 12 and 24 months post-EBRT, gastrointestinal and urinary toxicity were scored according to the Radiation Therapy Oncology Group (RTOG) scoring system (Table 2). Urinary stress incontinence was scored using the Ingelman Sundberg score. ${ }^{23}$ The PSA was monitored at 3, 6, 12, 18, 24, 30 and 36 months and then yearly.

\section{Results}

From April 2004 to June 2008, a total of 69 HIFU procedures were performed in 60 patients at our institution. Treatment was first-line in 48 patients and second-line in 12 patients (salvage therapy for local recurrence after EBRT). Among the 48 patients treated in first-line, HIFU treatment failed in 35 patients during the follow-up (biochemical failure using the Stuttgart definition [nadir $+1.2 \mathrm{ng} / \mathrm{mL}$ ] in 32 of 48 , and persistently positive biopsies with the start of salvage therapy occured in 3 of 48). Patients experiencing failure were informed of all management options and, depending upon their clinical condition, did or did not undergo salvage treatment. Eight patients $(8 / 35 ; 22.8 \%)$ chose second-line therapy (radiotherapy, $\mathrm{n}=7$; hormonal therapy, $\mathrm{n}=1$ ) and 27 chose close clinical surveillance and biochemical monitoring. The 7 patients who underwent salvage EBRT had undergone HIFU because they were not eligible for surgery or had refused surgery. The HIFU procedure was completed in 6 patients, but was discontinued in 1 patient due to a technical problem with the ultrasound detection. The mean number of HIFU sessions was 1.28 (a single session in 5 patients; 2 sessions in 2 patients). 
Table 1. Patients' characteristics before EBRT

\begin{tabular}{|c|c|c|c|c|c|c|c|c|c|c|c|}
\hline \multirow{2}{*}{ Patient } & \multirow{2}{*}{ Age } & \multicolumn{3}{|c|}{ PSA level, ng/mL } & \multirow{2}{*}{$\begin{array}{c}\text { Mean time } \\
\text { to reach PSA } \\
\text { nadir, months }\end{array}$} & \multirow{2}{*}{$\begin{array}{l}\text { Clinical } \\
\text { stage }\end{array}$} & \multicolumn{2}{|c|}{$\begin{array}{c}\text { D'Amico risk } \\
\text { category }\end{array}$} & \multirow{2}{*}{$\begin{array}{l}\text { Neoadju- } \\
\text { vant ADT }\end{array}$} & \multicolumn{2}{|c|}{ HIFU-related toxicity } \\
\hline & & $\begin{array}{l}\text { At diag- } \\
\text { nosis }\end{array}$ & $\begin{array}{c}\text { Nadir } \\
\text { after HIFU }\end{array}$ & $\begin{array}{l}\text { Before } \\
\text { EBRT }\end{array}$ & & & Low & $\begin{array}{c}\text { Inter- } \\
\text { mediate }\end{array}$ & & $\begin{array}{c}\text { Urinary } \\
\text { incontinence }\end{array}$ & $\begin{array}{l}\text { Gastro- } \\
\text { intestinal }\end{array}$ \\
\hline \#1 & 60 & 6.16 & 2.51 & 2.51 & 12 & $\mathrm{~T} 1$ & Yes & & No & No & No \\
\hline \#2 & 68 & 14.5 & 14 & 14.8 & 3 & $\mathrm{~T} 1$ & & Yes & No & No & No \\
\hline \#3 & 66 & 4.57 & 0.73 & 2.5 & 3 & $\mathrm{~T} 1$ & Yes & & No & No & No \\
\hline \#4 & 79 & 9.96 & 3.5 & 4.27 & 3 & $\mathrm{~T} 1$ & Yes & & No & No & No \\
\hline \#5 & 73 & 4.23 & 5.6 & 6.7 & 3 & $\mathrm{~T} 1$ & Yes & & No & No & No \\
\hline \#6 & 67 & 16 & 1.3 & 5.6 & 1 & $\mathrm{~T} 1$ & & Yes & No & No & No \\
\hline
\end{tabular}

HIFU: high-intensity focused ultrasound; PSA: prostate-specific antigen; EBRT: external beam radiotherapy; ADT, Androgen deprivation therapy.

Sextant prostate biopsies confirming the presence of a malignant tumour were performed after a persistently elevated PSA in 3 patients (Patients $\# 1, \# 2, \# 7$ ) and biochemical recurrence in 4 patients (Patients $\# 3, \# 4, \# 5, \# 6$ ). Bone scintigraphy and an abdominal CT scan excluded metastatic spread in all 7 patients. We recorded the individual patients' pre-EBRT characteristics (Table 1).

The mean interval between the HIFU procedure and EBRT was 11.7 months (range: 9-20). All patients underwent the complete EBRT course and reported that it was well-tolerated. There were no technical limitations. No patient received adjunctive ADT therapy. No patient died from prostate cancer. However, 1 patient died 3 months after salvage EBRT from sepsis after cardiac-device related infective endocarditis; this patient was excluded from the outcomes analysis (Patient \#1). The median follow-up for the 6 remaining patients was $36.5 \pm 10.9$ months (range: $24-54$ ).

The PSA level just before EBRT in these 6 patients was $6.08 \mathrm{ng} / \mathrm{mL}$ (range: $2.5-14.8$ ). The mean PSA nadir after EBRT was $0.62 \mathrm{ng} / \mathrm{mL}$ (range: $0.03-2.4$ ) and occurred within a median time of 22 months (range: 12-36 months). The mean PSA value at the end of follow-up was $0.22 \mathrm{ng} / \mathrm{mL}$ (range: 0.01-0.64). One patient experienced a biochemical failure (PSA nadir at 12 months: $2.4 \mathrm{ng} / \mathrm{mL}$ and PSA at 30 months: $5.2 \mathrm{ng} / \mathrm{mL}$ ). An ADT was introduced 30 months after EBRT. The disease-free survival rate was $83.3 \%$ at 36.5 months. We recorded the individual oncological data after EBRT (Table 2).
We also recorded the EBRT-related toxicity (Table 3 ). None of the 6 patients had experienced any gastrointestinal or urinary symptoms before EBRT. Two patients (Patients $\# 6, \# 7)$ experienced minor urinary symptoms and 1 patient (Patient \#3) experienced minor gastrointestinal symptoms 1 year post-EBRT. In 2 of these patients (\#3,\#7), symptoms persisted at 2 years. One case of hemorrhagic radiation cystitis (grade 3, RTOG rating scale, Patient \#2) occurred more than 1 year post-EBRT and the patient required surgical management. One patient (\#7) experienced persistent grade 1 urinary stress incontinence at 2 years. There were no cases of rectourethral fistula and no fatal complications.

\section{Discussion}

To our knowledge, only a single study has demonstrated that EBRT is a feasible salvage therapy after HIFU failure. ${ }^{20}$ In this study, 32 patients with local recurrence after HIFU treatment received salvage EBRT without adjunctive ADT and were followed up for a median of 37 months. High-risk or intermediate-risk patients constituted $85 \%$ of the cohort. The EBRT did not enhance toxicity. The 5-year disease-free survival rate was $64 \%$, similar to the rates reported for salvage EBRT after RP. ${ }^{24-27}$

We recorded a 3-year disease-free survival rate of $73.3 \%$, but our sample of patients was small and presented with less aggressive tumours (71.4\% low-risk, 28.6\% intermediaterisk). Salvage EBRT was not associated with any additional

\begin{tabular}{lccccccc}
\hline Table 2. Individual oncological data (n=6) \\
$\begin{array}{c}\text { Patient } \\
\begin{array}{c}\text { Interval between } \\
\text { HIFU and EBRT, } \\
\text { months }\end{array}\end{array}$ & $\begin{array}{c}\text { PSA nadir } \\
\text { after EBRT }\end{array}$ & $\begin{array}{c}\text { Time to } \\
\text { obtain PSA } \\
\text { nadir, months }\end{array}$ & $\begin{array}{c}\text { PSA value } \\
\text { at the end of } \\
\text { follow-up }\end{array}$ & $\begin{array}{c}\text { Follow-up } \\
\text { after EBRT, } \\
\text { months }\end{array}$ & $\begin{array}{c}\text { Biochemical } \\
\text { failure (nadir + } \\
\text { 2 ng/mL) }\end{array}$ & $\begin{array}{c}\text { Salvage } \\
\text { therapy }\end{array}$ \\
\hline$\# 2$ & 9 & 2.4 & 12 & 0.01 & 54 & Yes & ADT \\
$\# 3$ & 20 & 0.34 & 18 & 0.36 & 24 & No & No \\
$\# 4$ & 12 & 0.03 & 18 & 0.03 & 38 & 37 & No \\
$\# 5$ & 11 & 0.64 & 24 & 0.64 & 25 & No \\
$\# 6$ & 10 & 0.07 & 24 & 0.07 & 36 & No \\
\hline 7
\end{tabular}

HIFU: high-intensity focused ultrasound; PSA: prostate-specific antigen; EBRT: external beam radiotherapy; ADT, Androgen deprivation therapy. 
Ripert et al.

Table 3. Post-EBRT toxicity and urinary stress incontinence $(n=6)$

\begin{tabular}{|c|c|c|c|c|c|}
\hline \multirow[t]{2}{*}{ Toxicity } & \multicolumn{5}{|c|}{ RTOG rating* } \\
\hline & G1 & G2 & G3 & G4 & G5 \\
\hline \multicolumn{6}{|l|}{ At 1 year } \\
\hline - Bladder & 2/6 (\#6,\#7) & 0 & 0 & 0 & 0 \\
\hline - Bowel & 1/6 (\#3) & 0 & 0 & 0 & 0 \\
\hline \multicolumn{6}{|l|}{ At 2 years } \\
\hline - Bladder & $1 / 6(\# 7)$ & & $1 * * / 6(\# 2)$ & 0 & 0 \\
\hline - Bowel & $1 / 6(\# 3)$ & 0 & 0 & 0 & 0 \\
\hline Urinary incontinence & \multicolumn{5}{|c|}{ Stress Ingelman Sundberg score } \\
\hline & \multicolumn{2}{|c|}{1} & 2 & \multicolumn{2}{|c|}{3} \\
\hline - At 1 year & \multicolumn{2}{|c|}{ 1/6 (\#7) } & 0 & \multicolumn{2}{|c|}{0} \\
\hline - At 2 years & \multicolumn{2}{|c|}{ 1/6 (\#7) } & 0 & \multicolumn{2}{|c|}{0} \\
\hline \multicolumn{6}{|c|}{$\begin{array}{l}\text { EBRT: external beam radiotherapy; RTOG: Radiation Therapy Oncology Group. *RTOG rating: Grade 1, minor } \\
\text { symptoms requiring no treatment; Grade 2, outpatient management of symptoms: lifestyle (performance status) not } \\
\text { affected; Grade 3, distressing symptoms altering patient's lifestyle (performance status); hospitalization for diagnosis } \\
\text { or minor surgical intervention (e.g., urethral dilatation) might be required; Grade 4, major surgical intervention (e.g., } \\
\text { laparotomy, colectomy, or cystectomy) or prolonged hospitalization; Grade 5, fatal complication. }{ }^{* *} \text { Radiation cystitis. }\end{array}$} \\
\hline
\end{tabular}

ity nevertheless remained low. ${ }^{30}$ Patients whose PSA level does not drop sufficiently after a first HIFU treatment are probably not good candidates for repeat HIFU, as the PSA nadir is a predictive factor for biochemical failure. ${ }^{31}$

The chief limitation of our study is its small sample size. In fact, our retrospective review is virtually a series of case reports. In addition, our median follow-up was only 3 years. It is probably very difficult to draw a generalized conclusion on the efficacy of EBRT with a small population size. However, the literature on post-HIFU salvage EBRT is extremely scant probably because of the very few patients who have been offered such management. In our experience, only $20 \%$ (7/35) of patients who experienced a failure after HIFU treat-

toxicity. There were few EBRT-related gastrointestinal or urinary side effects, which tended to be minor. We encountered only 1 case of urinary stress incontinence. Urinary stress incontinence might be less of a problem when EBRT follows, rather than precedes, HIFU, since the reported incidence for salvage HIFU after EBRT failure is $49.5 \% .{ }^{28}$ All the EBRT procedures were well-tolerated. Neither tolerance nor technical limitations prevented the completion of the EBRT course. Studies comparing oncological outcomes after pre- and post-HIFU EBRT would be interesting, but difficult to interpret as the characteristics of first-line HIFU patients and first-line EBRT patients differ substantially.

Moreover, little is known about the management of patients who develop PSA failure subsequent to pre- and post-HIFU EBRT. There are no case series reports in the literature of RP for this group of patients, leaving minimally invasive options or ADT as the preferred options. Recently, Chalasani and colleagues published a case report concerning a 65-year-old male who received EBRT for localized prostate cancer and salvage HIFU. This patient underwent a radical cystoprostatectomy after conservative management failed because of a prostate-rectal fistula after salvage HIFU treatment. The authors' pathological findings suggested that the PSA failure following salvage HIFU was likely metastatic in nature, but that, unfortunately, there were currently no diagnostic tools which were sufficiently accurate to confirm this. The dilemma remained for physicians as to whether to offer definitive local treatment or systemic treatment in the form of ADT. ${ }^{29}$

All our patients underwent first-line HIFU; most of them in a single session, but some in 2 sessions. One of the advantages of HIFU is that it can be repeated, but little is known of the oncological outcomes upon repeat HIFU. An increase in morbidity has been reported on repeat HIFU, but morbid- ment underwent a curative salvage therapy. There is limited data available on the role of salvage EBRT in this setting. From that perspective, this manuscript is a useful addition to the literature.

Moreover, our choice to assess the oncologic efficacy of EBRT after HIFU using the Phoenix definition could be debatable. The Phoenix definition cannot in theory be applied to a prostate having received a preliminary physical treatment, and using this definition, our outcomes could be overestimated. However, no other validated definition is available at this time.

\section{Conclusion}

Our first clinical results seem to confirm the feasibility and tolerance of salvage EBRT after HIFU failure. The EBRT course was completed in all patients with very low morbidity at 12 months. Oncological outcomes are promising. Prospective studies with a longer follow-up are needed to identify factors predictive of success when using EBRT as salvage therapy after HIFU failure.

*Department of Urology-Andrology, Reims Academic Hospital, Reims, France; 'Department of Radiotherapy, Jean Godinot Institut, Reims, France

Competing interests: None declared.

This paper has been peer-reviewed. 


\section{References}

1. Yancik R. Population aging and cancer: a cross-national concern. Cancer J 2005;11:437-41.

2. Aus $G$, Abbou $C C$, Bolla $M$, et al. European association of Urology. EAU guidelines on prostate cancer. Eur Urol 2005;48:546-51.

3. Gelet A, Chapelon JY, Bouvier R, et al. Local control of prostate cancer by transrectal High intensity focused ultrasound therapy: preliminary results. J Urol 1999;161:156-62.

4. Blana $A$, Walter $B$, Rogenhofer $S$, et al. High intensity focused ultrasound for the treatment of localized prostate cancer: 5-year experience. Urology 2004;63:297-300.

5. Blana A, Murat FJ, Walter B, et al. First analysis of the long-term result with transrectal HIFU in patients with localized prostate cancer. Eur Urol 2008;53:1194-201.

6. Gelet A, Chapelon JY, Bouvier R, et al. Transrectal High intensity focused ultrasound for treatment of localized prostate cancer: factors influencing the outcomes. Eur Urol 2001;40:124-9.

7. Challacombe BJ, Murphy DG, Zakri R, et al. High intensity focused ultrasound for localized prostate cancer: initial experience with a 2-years follow-up. BJU Int 2009;104:200-4.

8. Blana A, Rogenhofer S, Ganzer R, et al. Eight years' experience with High intenstiy focused ultrasonography for treatment of localized prostate cancer. Urology 2008;72:1329-34.

9. Mearini L, D'Urso L, Collura D, et al. Visually directed transrectal High intensity focused ultrasound for the treatment of prostate cancer: a preliminary report on the Italian experience. J Urol $2009 ; 181: 105-11$; discussion 111-2.

10. Uchida $T$, Ohkusa $H$, Yamashita $H$, et al. Five years experience of transrectal high-intensity focused ultrasound using the Sonablate device in the treatment of localized prostate cancer. Int J Urol 2006;13:228-33.

11. Misraï V, Roupret M, Chartier-Kastler, et al. Oncologic control provided by HIFU therapy as single treatment in men with clinically localized prostate cancer. World J Urol 2008;26:481-5.

12. Heidenreich A, Aus $G$, Bolla $M$, et al. EAU guidelines on prostate cancer. Eur Urol 2008;53:68-80.

13. Lukka H, Waldron T, Chin J, et al. High-intensity focused ultrasound for prostate cancer: a practice guideline. Can Urol Assoc J 2010;4:232-6.

14. Soulié M, Beuzeboc P, Cornud F, et al. Recommandations 2007 en onco-urologie. Prog Urol 2007;17:1157-88

15. Poissonnier L, Chapelon JY, Rouvière 0 , et al. Control of prostate cancer by transrectal HIFU in 227 patients. Eur Urol 2007;51:381-7.

16. Blana A, Murat FJ, Walter B, et al. First analysis of the long-term result with transrectal HIFU in patients with localized prostate cancer. Eur Urol 2008:53:1194-201.

17. Stolzenburg JU, Bynens B, Do M, et al. Salvage laparoscopic extraperitoneal radical prostatectomy after failed High-intensity focused ultrasound and radiotherapy for localized prostate cancer. Urology 2007;70:956-60.
18. Liatsikos $E$, Bynens $B$, Rabenalt $R$, et al. Treatment of patients after failed High intensity focused ultrasound and radiotherapy for localized prostate cancer: salvage laparoscopic extraperitoneal radical prostatectomy. J Endourol 2008;22:2295-8.

19. Rebillard X, Soulié $M$, Chartier-Kastler E, et al. High-intensity focused ultrasound in prostate cancer: a systematic literature review of the French Association of Urology. BJU Int 2008;101:1205-13.

20. Pasticier $G$, Chapet 0 , Badet $L$, et al. Salvage radiotherapy after high-intensity focused ultrasound for localized prostate cancer: early clinical results. Urology 2008;72:1305-9.

21. Blana A, Brown SC, Chaussy C, et al. High-intensity focused ultrasound for prostate cancer : comparative définitions of biochemical failure. BJU Int 2009:104:1058-62.

22. Roach $M 3^{\text {rd }}$, Hanks $\mathrm{G}$, Thames $\mathrm{H} \mathrm{Jr}$, et al. Defining biochemical failure following radiotherapy with or without hormonal therapy in men with clinically localized prostate cancer: recommendations of the RTOGASTRO Phoenix Consensus Conference. Int I Radiat Oncol Biol Phys 2006;65:965-74

23. Ingelman-Sundberg A. Urinary incontinence in women. North Med 1953;50:1751-2.

24. Brooks JP, Albert PS, Wilder RB, et al. Long-term salvage radiotherapy outcome after radical prostatectomy and relapse predictors. J Urol 2005; 174:2204-8.

25. Catton C. Post-operative radiotherapy following radical prostatectomy. EAU Update Series 2005;3:107-16.

26. Ward JF, Moul JW. Rising prostate-specific antigen after primary prostate cancer therapy. Nat Clin Pract Urol 2005;2:174-82.

27. Stephenson AJ, Shariat SF, Zelefsky MJ, et al. Salvage radiotherapy for recurrent prostate cancer after radical prostatectomy. JAMA 2004;291:1325-32.

28. Murat FJ, Poissonnier L, Rabilloud M, et al. Mid-term results demonstrate salvage High-Intensity Focused Ultrasound (HIFU) as an effective and acceptably morbid salvage treatment option. Eur Urol 2008;55:640-9.

29. Chalasani $\mathrm{V}$, Martinez $\mathrm{CH}$, Williams $\mathrm{A}$, et al. Histological changes in the human prostate after radiotherapy and salvage high intensity focused ultrasound. Can Urol Assoc J 2010;4:e100-2.

30. Blana A, Rogenhofer $S$, Ganzer $R$, et al. Morbidity associated with repeated transrectal high-intensity focused ultrasound treatment of localized prostate cancer. World J Urol 2006;24:585-90.

31. Ganzer R, Rogenhofer S, Walter B, et al. PSA nadir is a significant predictor of treatment failure after High-intensity focused ultrasound (HIFU) treatment of localised prostate cancer. Eur Urol 2008;53:547-53.

Correspondence: Dr Thomas Ripert, Department of Urology and Andrology, CHU Reims, Reims, France, Rue du général Koenig, Reims 51 100, France ; thomas_ripert@yahoo.fr 